\title{
A galU mutant of francisella tularensis is attenuated for virulence in a murine pulmonary model of tularemia
}

\author{
Himangi R Jayakar ${ }^{1,2}$, Jyothi Parvathareddy ${ }^{1}$, Elizabeth A Fitzpatrick', Xiaowen R Bina', James E Bina', Fabio Re',
} Felicia D Emery ${ }^{1}$ and Mark A Miller ${ }^{1 *}$

\begin{abstract}
Background: A number of studies have revealed that Francisella tularensis (FT) suppresses innate immune responses such as chemokine/cytokine production and neutrophil recruitment in the lungs following pulmonary infection via an unidentified mechanism. The ability of FT to evade early innate immune responses could be a very important virulence mechanism for this highly infectious bacterial pathogen.

Results: Here we describe the characterization of a galU mutant strain of FT live vaccine strain (LVS). We show that the galU mutant was highly attenuated in a murine model of tularemia and elicited more robust innate immune responses than the wild-type (WT) strain. These studies document that the kinetics of chemokine expression and neutrophil recruitment into the lungs of mice challenged with the galU mutant strain are significantly more rapid than observed with WT FT, despite the fact that there were no observed differences in TLR2 or TLR4 signaling or replication/dissemination kinetics during the early stages of infection. We also show that the galU mutant had a hypercytotoxic phenotype and more rapidly induced the production of IL-1 $1 \beta$ following infection either in vitro or in vivo, indicating that attenuation of the galu mutant strain may be due (in part) to more rapid activation of the inflammasome and/or earlier death of FT infected cells. Furthermore, we show that infection of mice with the gall mutant strain elicits protective immunity to subsequent challenge with WT FT.

Conclusions: Disruption of the galU gene of FTLVS has little (if any) effect on in vivo infectivity, replication, or dissemination characteristics, but is highly attenuating for virulence. The attenuated phenotype of this mutant strain of FT appears to be related to its increased ability to induce innate inflammatory responsiveness, resulting in more rapid recruitment of neutrophils to the lungs following pneumonic infection, and/or to its ability to kill infected cells in an accelerated fashion. These results have identified two potentially important virulence mechanisms used by FT. These findings could also have implications for design of a live attenuated vaccine strain of FT because sublethal infection of mice with the galU mutant strain of FTLVS promoted development of protective immunity to WT FTLVS.
\end{abstract}

\section{Background}

Francisella tularensis (FT) is a gram-negative intracellular bacterium that is the causal agent of tularemia. The Francisellaceae family of bacteria has a single genus, Francisella, which has been divided into two species: 1) Francisella philomiragia (a muskrat pathogen) and 2)

\footnotetext{
*Correspondence: mamiller@uthsc.edu

'Department of Microbiology, Immunology, and Biochemistry, The University of Tennessee Health Science Center, 858 Madison Avenue, Memphis,

Tennessee 38163, USA

Full list of author information is available at the end of the article
}

Francisella tularensis. Francisella tularensis is further subdivided into four subspecies: tularensis (type A), holarctica (type B), novicida, and mediasiatica [1]. Of these, only subsp. tularensis and subsp. holarctica cause disease in humans [2]. FT tularensis is considered a prime candidate for use as a biological weapon because it is relatively easy to propagate and disseminate via aerosolization and because of the high morbidity and mortality associated with aerosol infection $\left(\mathrm{LD}_{50}<10 \mathrm{CFU}\right)[3,4]$. The live vaccine strain (FT LVS), which was derived from FT holarctica, is only moderately virulent in humans [5]
C Biomed Central

(C) 2011 Jayakar et al.; licensee BioMed Central Ltd. This is an open access article distributed under the terms of the Creative Commons Attribution License (http://creativecommons.org/licenses/by/2.0), which permits unrestricted use, distribution, and reproduction in any medium, provided the original work is properly cited. 
and retains virulence in mice. Because LVS causes an infection in mice that is similar to the human form of disease, the murine FT LVS infection model serves as an appropriate animal model of human tularemic disease [6-8].

FT is well adapted for growth and survival within host macrophages, as evidenced by its ability to inhibit phagosome/lysosome fusion and the respiratory burst, and to escape from the phagosome and replicate within the macrophage cytoplasm [9-11]. Moreover, it has been reported that the virulence of FT depends on its ability to escape into the host cytoplasm $[10,12,13]$. However, like many other successful pathogens, the key to the pathogenesis of FT may be in its ability to overcome, evade, and/or suppress innate host immune responses. For instance, FT is known to be relatively resistant to cationic antimicrobial peptides (CAMPs), which may in part be responsible for its ability to overcome host innate immunity $[14,15]$. In fact, it has been shown that FT mutant strains that are CAMP-sensitive are attenuated for virulence in mice $[16,17]$. FT is also able to evade (in part) innate immune detection because its lipopolysaccharide (LPS) has unusual modifications that render it immunologically inert and unable to stimulate TLR4 [17-19]. Indeed, FT novicida mutants that lacked these modifications and produced TLR4-stimulating LPS were able to induce stronger proinflammatory cytokine production and host innate responses resulting in rapid clearance and an attenuated phenotype in mice $[17,20]$. FT also appears to actively suppress acute inflammatory responses at early times after infection in lungs by a mechanism that has not yet been defined [21]. Following pulmonary infection of mice with FT, there is an initial lag in recruitment of neutrophils as well as a minimal proinflammatory cytokine response in the first 24-48 hours following infection with FT $[22,23]$. This quiescent period is typically followed by a massive neutrophil influx and profound upregulation of cytokine production that appears to contribute to FT pathogenesis [15,24,25]. The ability of WT FT to delay recruitment of neutrophils appears to be a critical virulence mechanism because FT mutants that fail to delay influx of neutrophils are rapidly cleared from the host and are attenuated for virulence $[17,20]$. Additionally, pretreatment of mice with rIL-12 resulted in early neutrophil recruitment to lungs and rapid immune clearance following infection with WT FT [26]. These data suggest that the kinetics, rather than the magnitude, of neutrophil recruitment at the site of infection are important for resolution of FT infection.

The efficacy of innate immune responses is largely dependent on interactions between host pattern recognition receptors with cell envelope components of the invading pathogen. Because WT FT appears to utilize undefined mechanism(s) to modulate innate immune signaling events to gain a survival advantage in mammalian hosts, we postulated that mutations that altered the cell envelope structure of FT would attenuate the virulence of the bacterium. In this report we have tested the hypothesis that gall is required for FT pathogenesis. The gall gene (FTL_1357) encodes for the production of UTP-glucose1-phosphate uridyl transferase (or alternatively UDPglucose pyrophosphorylase), an enzyme that catalyzes the formation of UDP-glucose from glucose-1-phosphate and UTP and is known to have a key role in biosynthesis of cell-envelope-associated carbohydrates (e.g. LPS and capsule) in a variety of bacteria [27-32]. The findings reported here revealed that disruption of the FT gall gene was highly attenuating in vivo, and that the reduction in virulence correlated with changes in the kinetics of chemokine production and neutrophil recruitment into the lungs following pulmonary infection. The gall mutant strain induced more rapid production of IL-1 $\beta$ in vivo and in vitro and it displayed a hypercytotoxic phenotype. We also found that mice that survived infection with the FT galU mutant strain developed protective immunity to subsequent challenge with WT FT.

\section{Results}

\section{Effect of galU mutation on growth and intracellular survival of FT in vitro}

The galu gene is highly conserved among the three major subspecies of FT (100\% identity between gall genes of SchuS4 and LVS, 98.5\% identity shared between FT novicida and LVS). In gram-negative bacteria, galU is typically part of an operon that is involved in galactose utilization and in the production of various exopolysaccharides $[27,30,31]$. The galu mutant strain characterized here was isolated from a random transposon library of FT LVS and was isolated as a polymyxin B hypersensitive strain (Figure 1A). The increased sensitivity of this gall mutant strain to cationic antimicrobials does not appear to be due to generalized outer envelope disintegrity because the mutant bacterium does not exhibit hypersensitivity to deoxycholate (an anionic bile acid) (Figure 1A) or the antibiotics chloramphenicol or tetracycline (data not shown).

The galU gene product is also known to be involved (but not required) in the catabolism of glucose and is required for the catabolism of galactose in bacteria and yeast $[31,33,34]$. Therefore, we predicted that the galU mutant strain would display a mild growth defect in minimal medium containing glucose as a sole sugar source, and would have a more marked growth defect when cultured in medium containing galactose as a sole source of sugar. To determine whether the galU mutant had a galactose utilization phenotype, we characterized its growth in MuellerHinton broth (MHB) supplemented with either glucose or galactose as a sole sugar source (it is important to note 


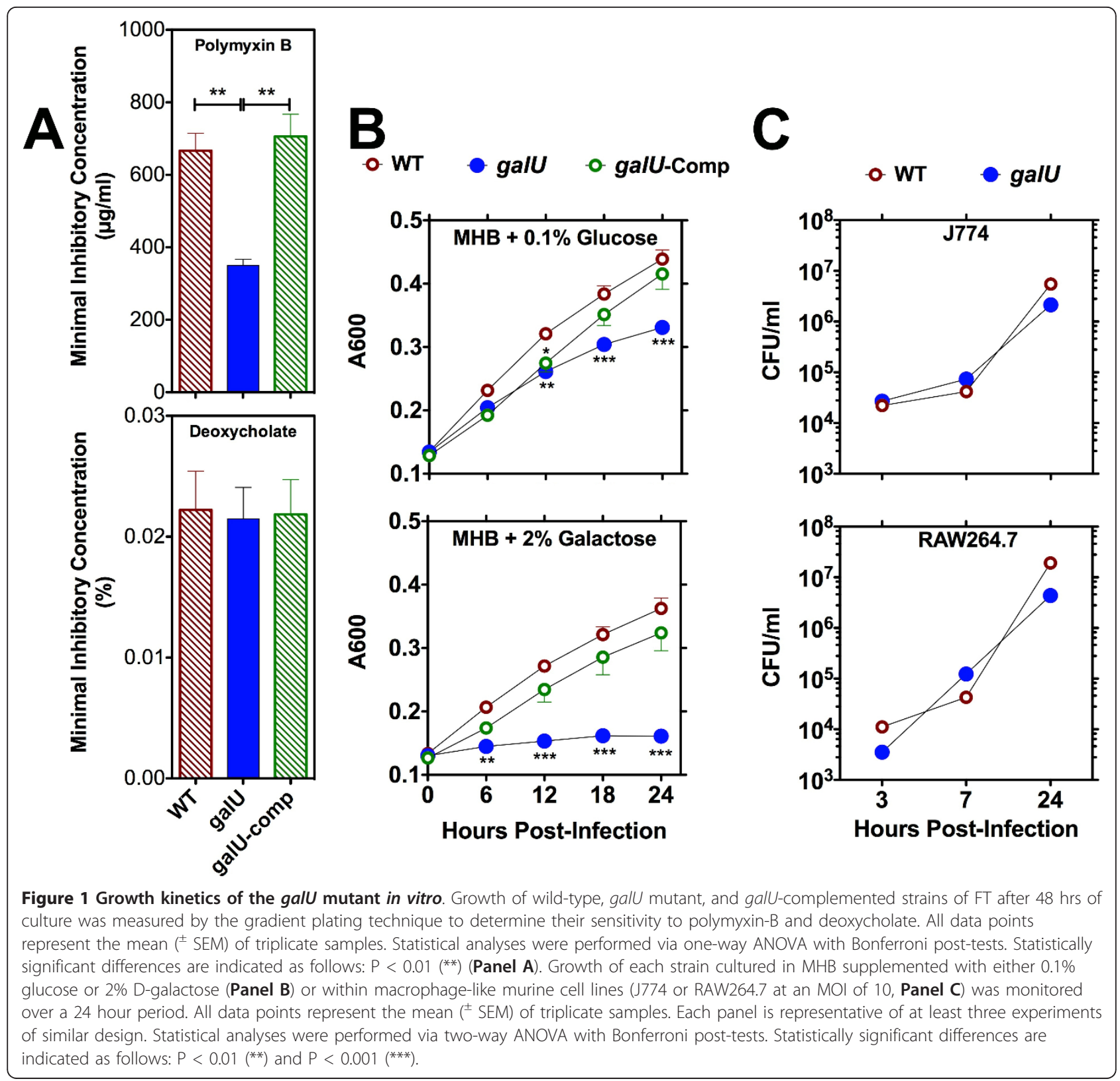

that our standard medium for culture of FT is MHB supplemented with $0.1 \%$ glucose as the sole source of sugar). As predicted, the galU mutant strain of FT displayed a mild growth defect in MHB supplemented with glucose and a severe growth defect in MHB supplemented with galactose. Complementation of the galU mutation restored WT growth kinetics in MHB supplemented with either glucose or galactose (Figure 1B).

To determine if mutation of the gall gene resulted in an intracellular growth defect, we evaluated the ability of the WT and gall mutant strains of FT to grow within murine macrophage-like cells in vitro. The replication kinetics of the galu mutant within J774 or RAW
264.7 cells were indistinguishable from those of the WT strain (Figure 1C), indicating that mutation of the gall gene had no effect on uptake or intracellular survival/ replication of the bacterium.

\section{Virulence of the galU mutant in vivo}

To determine whether the galU gene is important for FT virulence, C57Bl/6J mice (5/group) were inoculated intranasally with $5 \times 10^{4} \mathrm{CFU}\left(50 \times \mathrm{LD}_{50}\right)$ of either the galu mutant or WT FT and then were monitored for 15 days. Each of the mice challenged with the gall mutant experienced transient weight loss but survived and completely cleared the infection, while all of the mice 
challenged with WT FT lost weight continually until they succumbed to tularemia (Figure $2 \mathrm{~A}$ and $2 \mathrm{~B}$ ). An additional challenge trial in which $\mathrm{C} 57 \mathrm{Bl} / 6$ mice (4/group) were challenged with higher numbers of the gall mutant (up to $10^{7} \mathrm{CFU}$ ) revealed that this mutant is highly attenuated, with an $\mathrm{LD}_{50}$ that is at least 5 logs higher than that of WT FT (Figure 2C). Moreover, trans-complementation of the galU mutation completely restored virulence of the mutant strain (Figure 2A). These findings indicated that FT virulence in mice is dependent on the expression of a functional galu gene product.

To determine whether the reduced virulence of the galu mutant was the result of defective replication and/or dissemination of the bacterium in vivo, we performed a kinetic analysis of bacterial burdens following infection. C57Bl/6J mice (16/group) were challenged with $5 \times 10^{4} \mathrm{CFU}$ of either the galU mutant or WT FT and then four mice were sacrificed at each time point $(24,48,72$, and $96 \mathrm{~h}$ post-infection) for bacterial burden determinations from the lungs, livers, and spleens (Figure 3). The bacterial burdens observed in the gall mutant- and WT-infected mice were similar in each of the tissues for the first $48 \mathrm{~h}$, indicating that mutation of galu did not confer any significant defects in replication or dissemination of FT in vivo. However, the burdens observed in the galu mutant-infected mice were significantly lower $(p<0.01)$ in the spleens and livers $(p<0.001)$ of infected mice at the $96 \mathrm{~h}$ time point. Collectively, these results reveal that despite its normal replication/dissemination phenotypes, the galU mutant is more readily cleared than WT FT.

\section{Mutation of galU alters the kinetics of innate immune responses}

To determine whether differences in innate immune recognition of infection might be responsible for the dramatic difference in the outcome of disease with the gall mutant vs. WT FT, we analyzed the kinetics of immune cell infiltration into the lungs following infection. BALF were collected from each mouse at the time of sacrifice and a series of flow cytometric analyses was performed. The numbers of macrophages, dendritic cells, and NK cells recruited into the lungs of mice infected with the galU mutant and WT FT were similar at each time point (data not shown). However, higher numbers of neutrophils were observed in the lungs of mice infected with the galU mutant at the 24- and 48-hour time points, with peak numbers of neutrophils measured at 48 hours postinfection (Figure 4A). In contrast, the kinetics of recruitment of neutrophils into the lungs of mice infected with WT FT was much slower (Figure 4A), peaking five days post-infection (data not shown).

Using a Luminex multiplex kit, we also measured the levels of a panel of cytokines/chemokines in the BALF collected from each mouse and found that the levels of

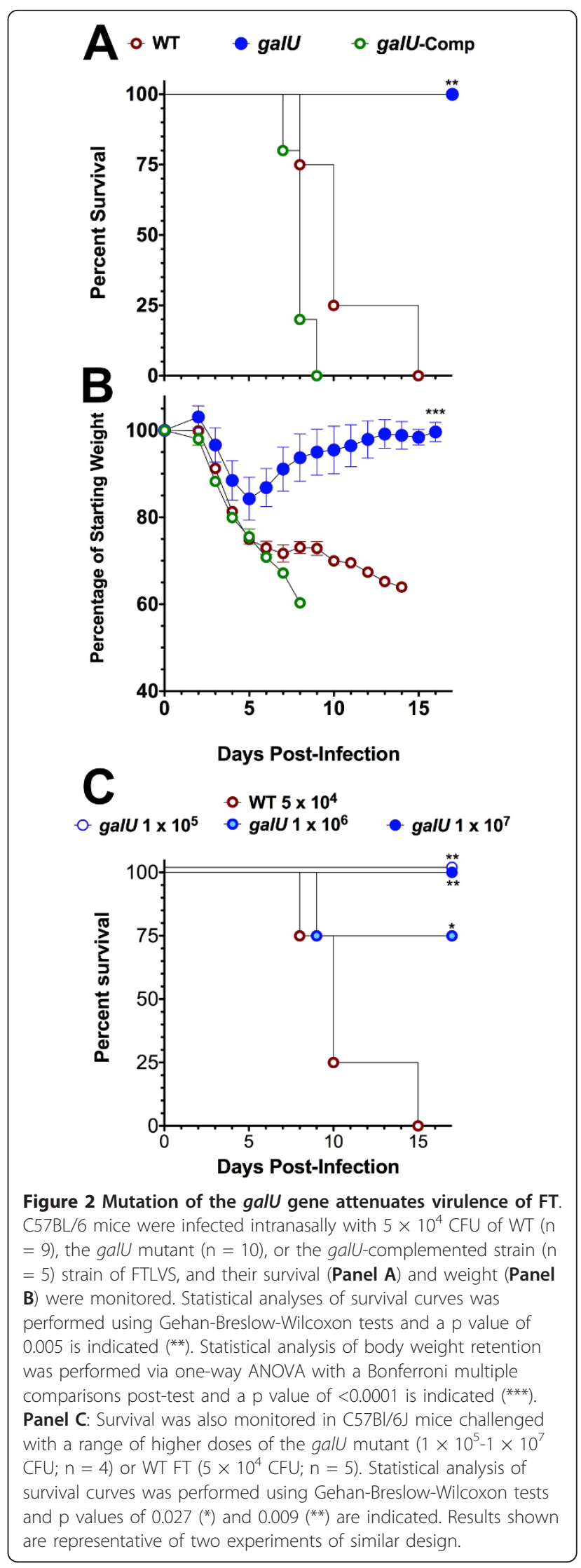




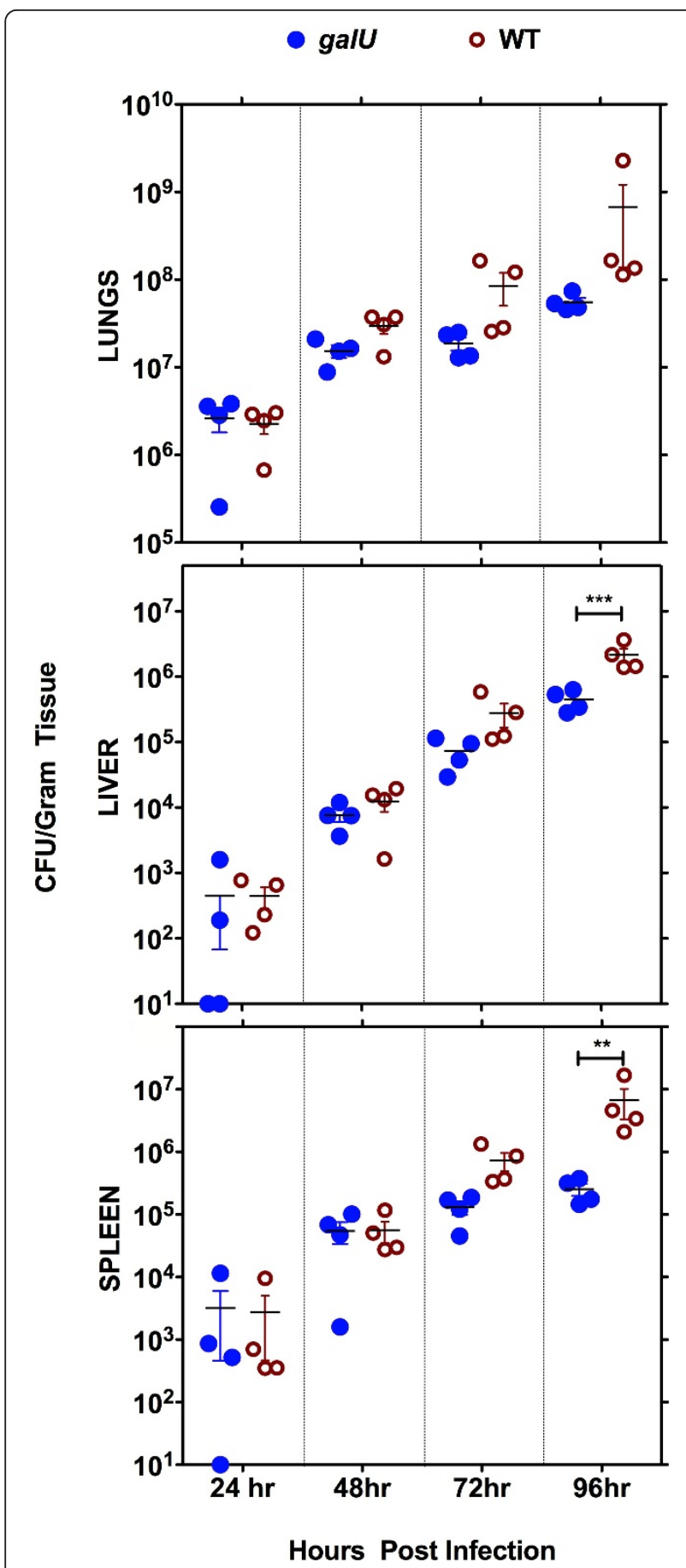

Figure 3 Mutation of the galU gene does not attenuate infectivity of FT in vivo. C57BL/6 mice (4/group) were infected intranasally with $5 \times 10^{4} \mathrm{CFU}\left(50 \times \mathrm{LD}_{50}\right.$ for FT LVS) of either the WT or galU mutant strain of FT LVS. Organs were harvested at 24, 48,72 and 96 hours p.i. and CFU/g of organ was determined for lungs, liver, and spleen. The lower limit of detection was 20 CFU/g. Statistical analyses were performed via two-way ANOVA with a Bonferroni multiple comparisons post test and all significant differences are indicated as follows: ${ }^{*} P<0.01$ and ${ }^{* *} P<0.0001$ The data shown is representative of two independent experiments of similar design. several neutrophil chemoattractants CXCL1/KC [35], granulocyte colony stimulating factor or G-CSF [36], CXCL10/IP-10 [37], TNF- $\alpha$ [38], MIP-1 $\alpha /$ CCL3 and MIP-1 $\beta /$ CCL4 [39], CXCL2/MIP-2 [40], and CCL2/ MCP-1 [41] were all present at significantly higher levels in the lungs of galu mutant-infected mice $(p<0.05)$ at the 24 or $48 \mathrm{~h}$ time points (Figure $4 \mathrm{~B}$ and $4 \mathrm{C}$ ), correlating well with the peak of neutrophil recruitment at $48 \mathrm{~h}$ post-infection. The levels of these same chemokines/ cytokines peaked in the lungs of WT FT-infected mice 72-96 hours post-infection (data not shown), corresponding well with the peak of neutrophil recruitment into the lungs on day five post-challenge.

It was recently reported that mutations that result in alterations in LPS structure, making the bacterium more likely to be recognized through TLR4 signaling, could result in robust chemokine expression and early neutrophil recruitment $[17,20]$. To determine if the altered kinetics of innate immune responses observed for the galU mutant strain resulted from gross alterations to its LPS structure, we extracted LPS from WT, gall mutant, and $w b t A$ mutant (O-antigen deficient) strains of FT and performed Western blot analysis using a FT LPS-specific mAb. No obvious alteration in LPS laddering was observed, suggesting that mutation of galU did not result in gross changes in synthesis of the O-antigen component of LPS (Figure 5A). We also analyzed the ability of LPS derived from the galU mutant to initiate TLR4mediated signaling. Using HeLa cells that stably express either TLR2 or TLR4/MD2 that had been transfected with a vector bearing a NF $\kappa \mathrm{B}$-responsive luciferase reporter construct, we determined that neither galU mutant or WT FT lysates were able to stimulate TLR4 while both stimulated TLR2 to the same extent (Figure $5 \mathrm{~B})$, suggesting that the lipid A portion of the mutant LPS was not altered.

To further investigate whether the galU gene resulted in gross change(s) to the outer envelope of FT, experiments were performed to measure the relative sensitivity of galU mutant and WT FT to serum components. The galU mutant, WT, and galU-complemented strains of FT all displayed a similar pattern of serum sensitivity. In contrast, an $\mathrm{O}$-antigen-deficient ( $\Delta w b t A$ mutant) strain of FT was highly sensitive to serum. Interestingly, the galU, WT, and galU-complemented strains were equally sensitive to heat-inactivated serum, while the $w b t A$ mutant strain displayed no sensitivity to serum that had been heat inactivated (Figure 5C).

\section{IL-1 expression/activation induced by the galU mutant} vs. WT FT

Activation of the AIM2 inflammasome and production of IL-1 $\beta$ and IL-18 are known to be a critical component of the innate immune response to FT infection [42]. 

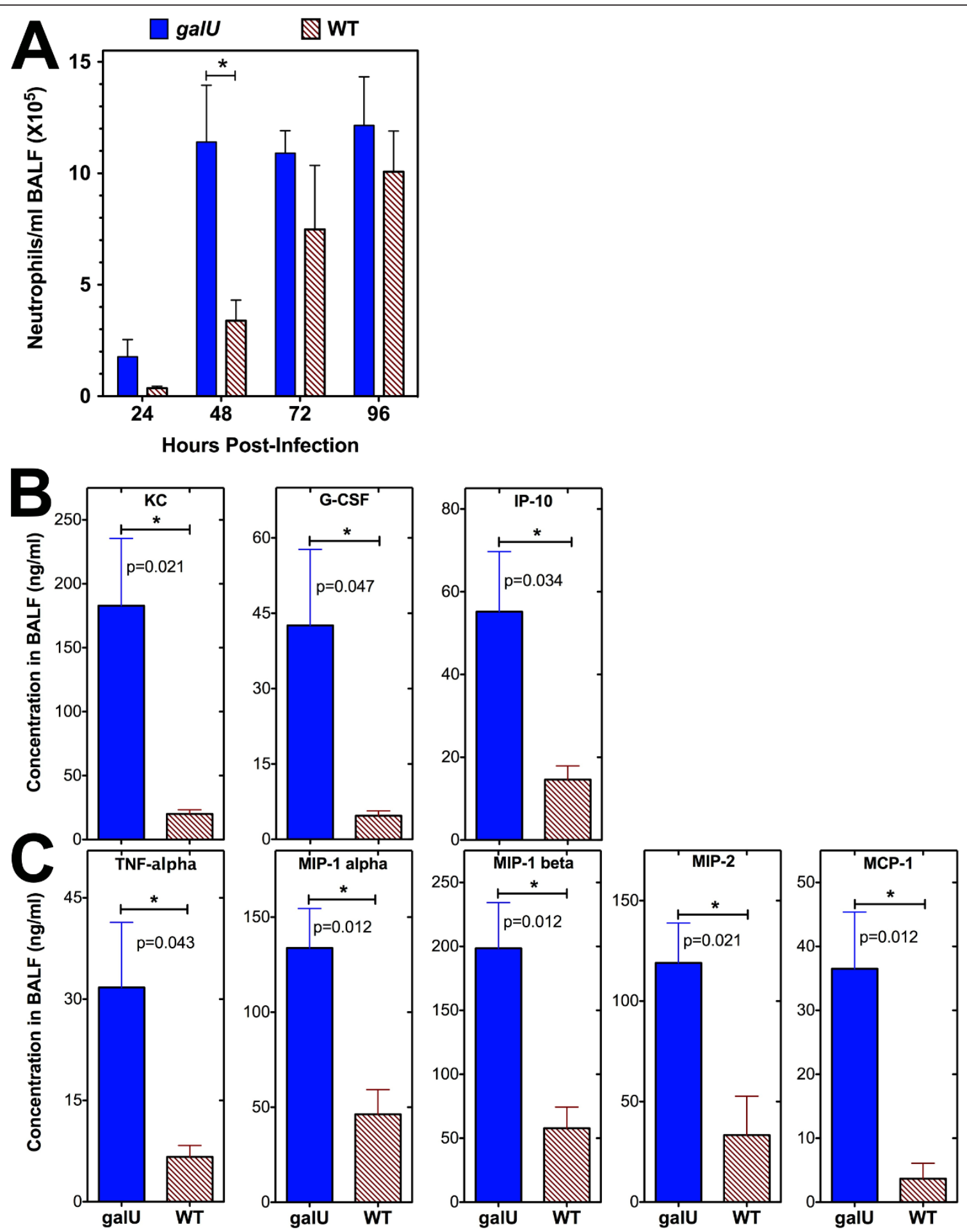

Figure 4 Neutrophil recruitment and chemokine expression in the lungs following infection with the galU mutant. C57Bl/6J mice (4/ group) were infected intranasally with $5 \times 10^{4} \mathrm{CFU}\left(\right.$ or $50 \times L_{50}$ ) of either the WT or galU mutant strain of FT and BALF was collected from individual mice at $24,48,72$ and 96 hours post-infection. Flow cytometric analyses were performed on the cells recovered from BALF to determine the numbers of neutrophils at each timepoint. Statistical analyses were performed via two-way ANOVA with a Bonferroni multiple comparisons post-test and statistically significant differences $(P<0.05)$ are indicated $\left(^{*}\right)$ (Panel A). The concentrations of KC, G-CSF, MIG, and IL10 (Panel A) and TNF- $\alpha$, MIP-1 $\alpha$, MIP-1 $\beta$, MIP-2, and MCP-1 (Panel B) in BALF at the 24 and 48 hour time points, respectively, were determined using a Luminex multiplex kit. Statistical analyses were performed using unpaired t tests. Statistically significant differences $\left(^{*}\right)$ and $p$ values are indicated in each panel. The data shown is representative of three independent experiments of similar design. 


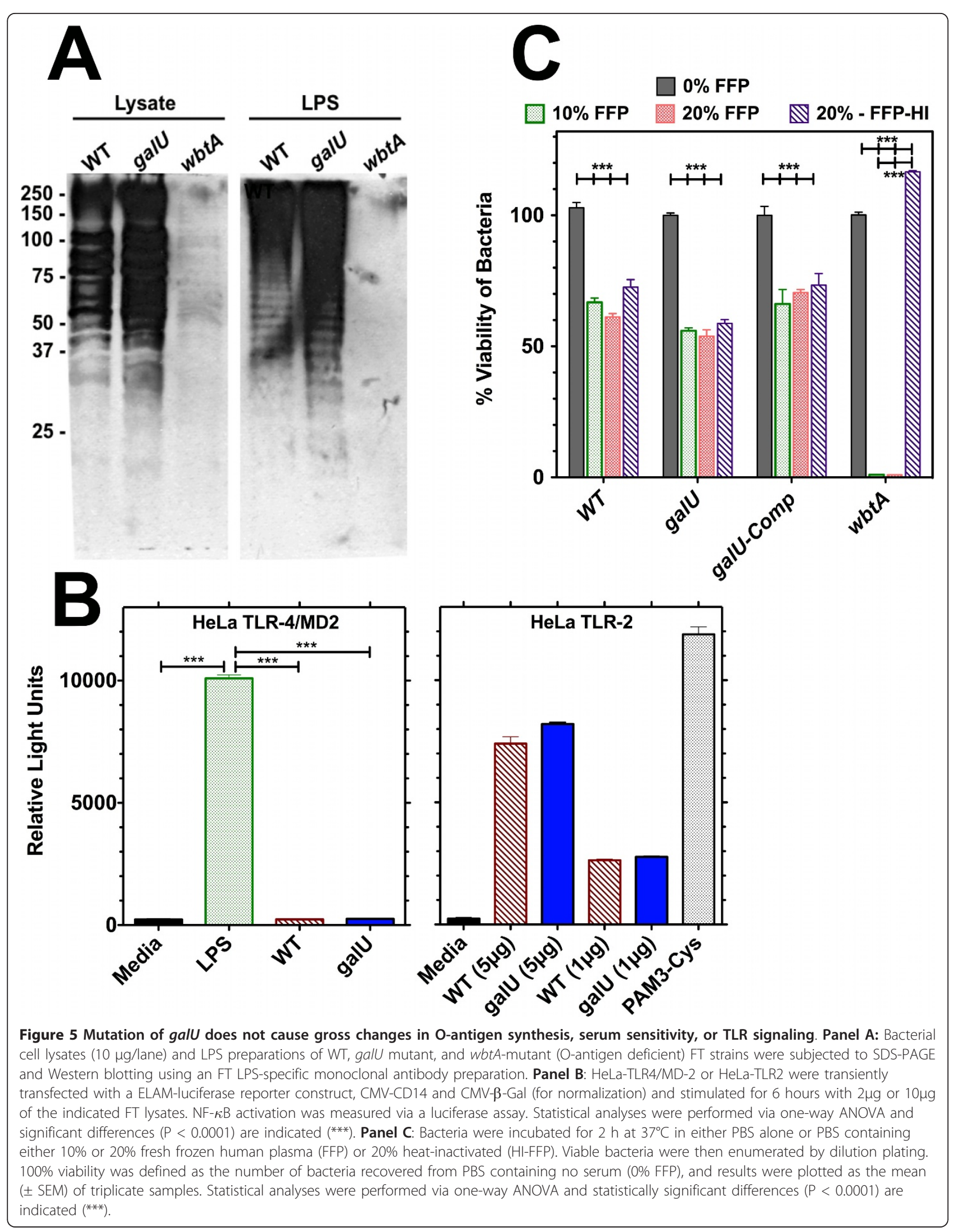


We compared the kinetics of IL-1 $\beta$ production following infection (in vitro and in vivo) with either the galu mutant or WT strain of FT. RNase protection analysis revealed that IL-1 $\beta$ mRNA levels (as well as those of several other cytokines) were similar in bone marrowderived dendritic cells (BMDC) that had been infected for $8 \mathrm{~h}$ with either the galu mutant, WT, or galucomplemented strains of FT (Figure 6A), confirming the comparable abilities of the galU mutant and WT strains to stimulate TLR-mediated events such as cytokine expression. However, $24 \mathrm{~h}$ after infection of a macrophage-like cell line (THP-1) or BMDCs with the galU mutant, the amount of IL- $1 \beta$ released into culture supernatants was significantly higher $(p<0.0001$ and $p<0.01$, respectively) than was observed following infection with WT FT (Figure 6B). The gall mutant also induced accelerated kinetics of IL-1 $\beta$ protein production in vivo (Figure 6C). Moreover, the kinetics of IL-1 $\alpha$ protein production is more rapid following infection with the galu mutant strain of FT (Figure 6C).

\section{Cytotoxicity of the galU mutant}

In light of the findings that mutation of the galu gene resulted in altered kinetics of innate signaling and earlier production of IL-1 $\beta$ than was observed with WT FT, we speculated that the galu mutant might induce death of the host cell more rapidly than WT FT. To investigate this possibility, we evaluated the relative abilities of the

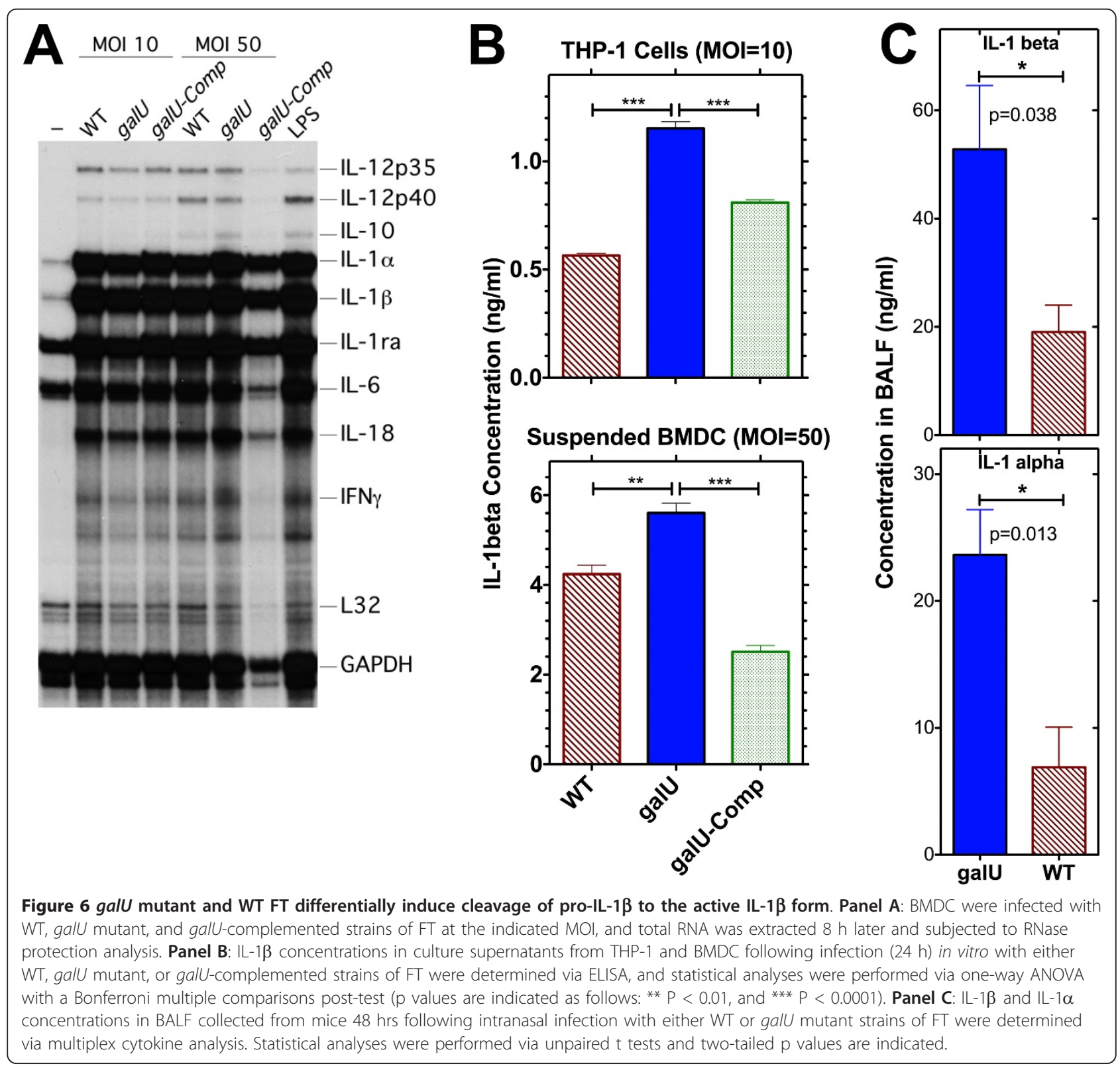


galU mutant and WT FT strains to kill their host cells in vitro. A macrophage-like cell line (J774) was infected with either the gall mutant or WT FT strains at an MOI of 100 and incubated for 24 hours. LDH activity in the culture medium was then determined as a measure of host cell death. A significantly higher amount of LDH activity was measured in the supernatants of J774 cells that had been infected with the galU mutant compared to those infected with WT FT $(p<0.0001)$, indicating that the galu mutant was hyper-cytotoxic. Complementation of the galu mutation in trans partially restored the cytotoxicity phenotype. For comparative purposes, a $w b t A$ mutant strain of FT was also included and was shown to have cytotoxicity characteristics similar to those of WT FT (Figure 7).

\section{Immunization with the galU mutant confers immunity to WT FT challenge}

Because infection with the galU mutant elicited a robust innate immune response and infected mice were able to clear the infection, we assessed the efficacy of the gall

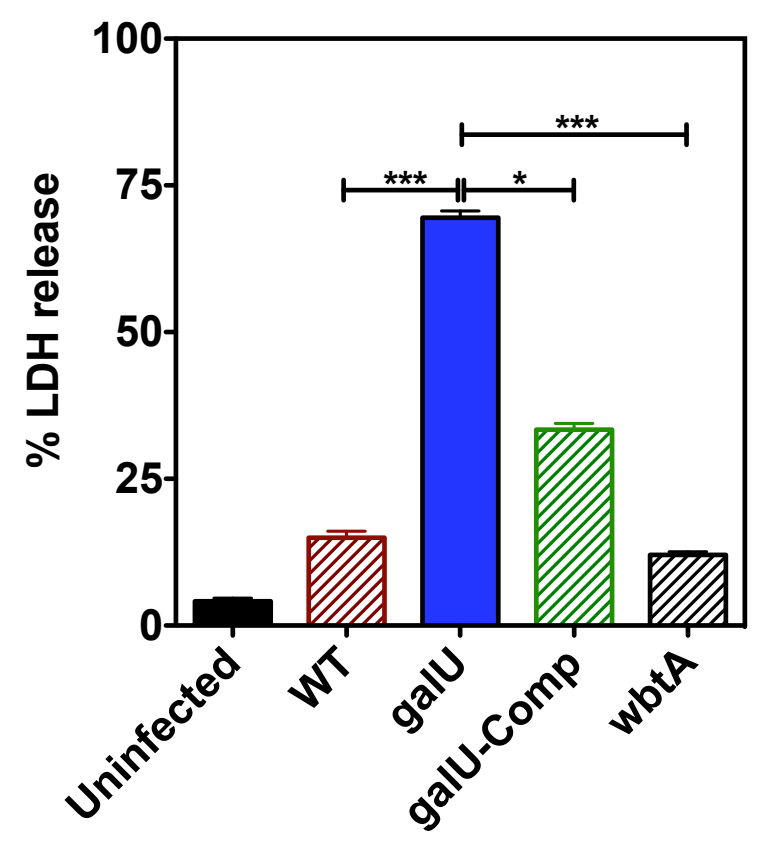

Figure 7 Mutation of the galU gene increases cytotoxicity of FT. Murine macrophage-like cells (J774) were infected with the WT, galU mutant, the galU-complemented, or wbtA mutant (O-antigendeficient) FT LVS strains at an $\mathrm{MOI}$ of 100 . Host cell death was determined by measuring $\mathrm{LDH}$ released from infected cells 24-hours post-infection. All data points represent the mean $( \pm$ SEM) of triplicate samples and the data shown is representative of three experiments of similar design. Statistical analyses were performed via one-way ANOVA with a Bonferroni multiple comparisons posttest ( ${ }^{* *}$ indicates a p-value of $<0.0001$ ). mutant strain as a live attenuated vaccine strain. Two months following the initial inoculation, mice that survived infection with the galU mutant, as well as a naïve group of mice, were challenged with a large dose of WT $\left(50 \times \mathrm{LD}_{50}\right)$ via the intranasal route and were monitored for survival. The gall mutant-immunized mice experienced transient weight loss following challenge, but displayed no other visible symptoms of tularemic disease and survived the infection. In contrast, each of the naive mice displayed the typical visible signs of tularemia (lack of grooming, hunched posture, reduced motor activity, etc.) and succumbed to WT FT infection by day 8 postchallenge (Figure 8).

\section{Discussion}

A major focus of FT research continues to be the identification of virulence-mechanisms used by this extremely virulent pathogen. A number of virulence determinants have been identified, but there remains much to discover regarding the virulence mechanisms used by FT to survive and cause disease within its mammalian hosts. In this report we show that mutation of galU results in a dramatic attenuation of FTLVS virulence that appears to be unrelated to any in vivo infectivity or growth defects. Although it is known that mutation of the gall gene leaves some other bacterial pathogens attenuated for virulence $[27,32,43,44]$, this is the first report examining the role of galu in the pathogenesis of FT.

Neutrophils are a critical component of the innate immune responses to bacterial infection, and the recruitment of these cells into the lungs following pneumonic infection typically peaks by 48 -hours post-infection [45-47]. However, it has been reported elsewhere [22,25] and confirmed here that neutrophil recruitment following wild type FT infection in the lungs is not detected until approximately $72 \mathrm{~h}$ post-infection. Because it is known that neutrophils are required for control of FT infection [48], it is reasonable to speculate that the ability of FT to delay the kinetics of neutrophil recruitment into the lungs following pulmonary infection may be an important virulence determinant. Interestingly, a comparative analysis following pulmonary infection of mice with the galU mutant and WT strains of FT revealed that the kinetics of neutrophil recruitment (and production of chemokines/cytokines involved in neutrophil recruitment) occurs much more rapidly following infection with the gall mutant (peaks at $48 \mathrm{~h}$ post-infection). Kinetic analyses of bacterial burdens in the lungs, spleens, and livers of mice following infection with the galu mutant and WT strains of FT revealed that the two strains disseminated and replicated at comparable rates, but the bacterial burdens in galU-infected animals became significantly lower than in WT-infected animals by $72 \mathrm{~h}$ post-infection. The significant difference in bacterial 


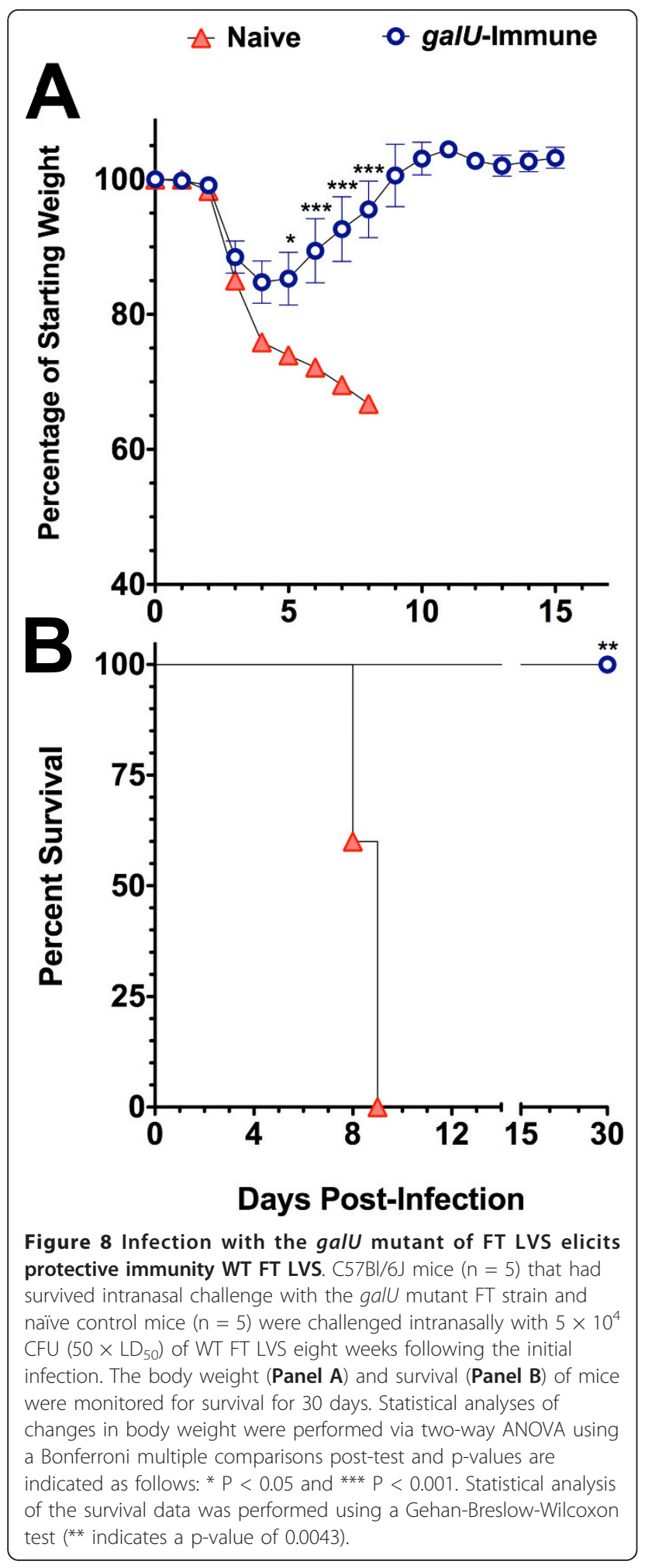

burdens observed in galu mutant-vs. WT FT-infected mice 3-4 days post-infection may have been (at least in part) due to differences in the kinetics of neutrophil recruitment.
It remains unclear whether FT actively suppresses innate immune responses during the early stages of infection, or if the delayed response is due to poor recognition of FT through host pattern recognition receptors. It has been well documented that FT produces an atypical LPS that is not recognized via TLR4 [49-51] and that FT is recognized via the TLR2 signaling pathway [52-55]. Because the gall gene has been shown to be important for LPS production $[27,31,32,43,56]$ in a number of other bacterial systems, we performed a series of studies to determine whether differences in the LPS expressed by the FT galU mutant might contribute to its reduced virulence. A western blot of both bacterial extracts and LPS preparations revealed no obvious differences in the $\mathrm{O}$-antigen laddering between the galU mutant and WT strains of FT, suggesting that mutation of galu did not have any gross effects on $\mathrm{O}$-antigen synthesis. Because it has been reported elsewhere [57] and confirmed here (wbtA mutant) that the absence of $\mathrm{O}$-antigen is a major determinant of susceptibility to complement-mediated killing, our findings that the galu mutant displayed a WT serum sensitivity phenotype also suggested that $\mathrm{O}$-antigen synthesis was not significantly altered by mutation of the galu gene. This finding contrasted with reports that galU mutant strains of $P$. aeruginos $a$ and $V$. cholerae displayed increased serum sensitivity $[31,44]$. We also observed no differences between the galu mutant and WT strains of FT with respect to signaling via the TLR2 and TLR4 recognition pathways. It remains possible that mutation of galU results in minor $\mathrm{O}$ antigen compositional changes, alterations in the core oligosaccharides, or differences in the carbohydrate modification of surface proteins of FT. Moreover, in light of the published finding that mutations causing alterations in the lipid A of FT novicida $[17,20]$ are highly attenuating for virulence in vivo (possibly due to altered kinetics of cytokine/chemokine production and neutrophil mobilization), we posit that mutation of the galU gene may have an impact on the lipid A moieties of FT. A complete analysis of the carbohydrate components of the FT gall mutant is needed to identify such differences.

Recent studies have revealed that the innate immune response to FT infection is complex and involves multiple signaling pathways. Others and we have previously shown that FT elicits a powerful inflammatory response that is primarily mediated by TLR 2 and caspase- 1 activation [52-55]. More recently, it has been demonstrated that the AIM-2 inflammasome mediates caspase- 1 activation and secretion of mature IL- $1 \beta$ and IL-18 during FT infection $[42,58,59]$. We predicted that the ability of the galU mutant strain of FT to accelerate the kinetics of inflammatory cytokine production/neutrophil mobilization in vivo might be due to more rapid activation of the inflammasome. To address this hypothesis, we measured 
IL-1 $\beta$ protein production by either THP-1 cells or BMDCs infected for $24 \mathrm{~h}$ in vitro and found that the gall mutant induced higher concentrations of IL-1 $\beta$ than did WT FT. However, RNase protection assays revealed that the differences in IL- $1 \beta$ production by galu mutant-vs. WT FT-infected cells were not the result of differential transcription of the IL- $1 \beta$ gene and, therefore, were likely due to more robust activation of the inflammasome. Our findings that production of IL-1 $\beta$ (as well as IL-1 $\alpha$ ) was induced significantly earlier in the lungs of gall mutant vs. WT FT-infected mice were also consistent with the hypothesis. Moreover, we showed that macrophage-like J774 cells infected in vitro with the galu mutant are killed more rapidly than those infected with WT FT and that WT cytotoxicity could be partially restored by complementation in trans with the gall gene. These findings were consistent with the possibility that the gall mutant more rapidly activates the inflammasome that, in turn, initiates host cell death via pyroptosis and limits the ability of the bacteria to replicate [60]. Based on findings with other mutant strains that display a hypercytolytic phenotype $[61,62]$, it could be speculated that such a change in the in vivo life cycle of FT could result in significant attenuation of virulence like that observed for the galu mutant. Overall, the findings shown here with FTLVS $\Delta$ gall are consistent with recently published studies showing that mutation of either $m v i N$ (FTL_1305 [63]) or ripA (FTL_1914 [64]) results in attenuated FT strains that activate the inflammasome more efficiently. Additional studies designed to delineate the signaling pathway(s) that enable early inflammasome activation by the galU mutant strain of FT are warranted.

Because the gall mutant was so severely attenuated for virulence, in spite of its normal ability to replicate and disseminate in vivo, and because there still is no well-defined and efficacious vaccine for FT, we performed a vaccine trial with the galu mutant strain. Mice that had been infected with the galu mutant and had survived the infection were challenged intranasally two months later with a large dose $\left(50 \times \mathrm{LD}_{50}\right)$ of WT FT LVS and all were found to be immune to FT. These findings, coupled with the fact that the galU gene is $100 \%$ conserved between the LVS and Schu S4 strains, suggest that a galU mutant strain in the Schu S4 background could have strong prophylactic potential as a live attenuated vaccine strain. Studies to characterize galU in FT SchuS4 are currently underway in our laboratory.

\section{Conclusions}

Disruption of the galU gene of FTLVS has little if any effect on its infectivity, replication, or dissemination in vitro, but it resulted in highly significant virulence attenuation. The reduced virulence of the galu mutant appears to be related to its increased ability to induce innate immune responses following infection. Inflammatory responses and chemokine/cytokine production elicited by WT FT proceeds with much slower kinetics than typically observed for other bacterial pathogens. In contrast, the kinetics of chemokine/cytokine expression and neutrophil recruitment is more rapid following infection with the galU mutant strain, likely resulting in more rapid uptake and killing of bacteria by neutrophils. These studies also revealed that disruption of the galU gene results in a hypercytotoxic phenotype that could be due (at least in part) to activation of the AIM-2 inflammasome. The accelerated death of cells infected with the gall mutant strain presumably interferes with the normal replicative cycle of the bacterium, resulting in the significant difference in bacterial burdens in the liver and spleen of mice infected with the gall mutant vs. WT strains of FTLVS observed 4 days post-infection and contributing to the reduction in FTLVS $\Delta$ galU virulence. These findings underscore the need for studies designed to understand the mechanisms used by WT FT to alter the kinetics of innate immune responses following infection. A thorough comparative analysis of the outer envelope of the WT and galu mutant strains of FTLVS coupled with a more detailed analysis of the innate signaling that results following infection with these two strains of FT could lead to a better understanding of the ability of FT to avoid detection by the innate immune system during the early stages of infection. The findings presented here also suggest that a galU mutant strain of FT has high potential as a platform for development of a live attenuated tularemia vaccine strain.

\section{Methods}

\section{Bacteria and Culture Conditions}

FTLVS was a kind gift of Dr. Karen Elkins (FDA, Bethesda, MD). The FTLVS galu mutant strain was identified by screening a LVS transposon mutant library for mutants exhibiting elevated susceptibility to polymyxin B. Transposon insertion in to the gall gene was verified by DNA sequencing and the polymyxin B hypersensitive phenotype was verified by complementation. The results of this screen will be described in a future publication. FT strains were grown at $37^{\circ} \mathrm{C}$ in Mueller-Hinton (DIFCO/Becton Dickinson, Sparks, MD) broth modified with $2.5 \%$ ferric pyrophosphate, $0.1 \%$ glucose, and $10 \%$ cysteine $(\mathrm{MMH})$. The galU mutant was grown under kanamycin selection $(10 \mu \mathrm{g} / \mathrm{mL})$. Complementation studies were performed as follows. The gall gene was amplified by PCR from the LVS genome using primers: forward primer: 5'-CTCGTGGATCCGCTAAAATGAAAATAAGAAAAGC-3' and reverse primer: 5'ATCGCTAATCGATAAGCTATCTATTTTGAAGG-3'. The resulting amplicon was digested with BamHI and 
ClaI restriction endonucleases before being ligated to similarly digested pXB167 [65], which placed the galu gene downstream and in the same orientation as the constitutively expressed orf5 promoter. The resulting plasmid, pXB167-galu, was then introduced into the indicated strains by electroporation as previously described $[15,65]$. The galU-complemented strain was grown in presence of kanamycin $(10 \mu \mathrm{g} / \mathrm{mL})$ and carbenicillin $(350 \mu \mathrm{g} / \mathrm{mL})$. Bacterial stocks were made from overnight cultures of bacteria grown to $\mathrm{OD}_{600}$ of $0.7-0.9$, and aliquots were frozen at $-80^{\circ} \mathrm{C}$.

\section{Antimicrobial Susceptibility Determination}

Antimicrobial susceptibility was determined by the gradient agar plate method $[15,66]$. The gradient agar plates were prepared in $90 \mathrm{~mm} \times 90 \mathrm{~mm}$ Petri plates as follows. Thirty-five milliliters of BHI-chocolate agar (without the test compound) was poured into the square Petri dish and allowed to harden as a wedge by elevating one side of the plate. After the agar solidified, $35 \mathrm{~mL}$ of BHI-chocolate agar containing the test compound were added to the leveled plate and allowed to solidify. The antibiotic gradient plates were allowed to develop for $2 \mathrm{~h}$ and inoculated within $3 \mathrm{~h}$ after preparation. Growth was measured after two days of incubation at $37^{\circ} \mathrm{C}$. All tests were performed in triplicate. Minimal inhibitory concentrations (MIC) were determined as follows: $\mathrm{MIC}=$ distance of growth $(\mathrm{mm}) \times$ concentration of drug $(\mathrm{ex} . \mu \mathrm{m} / \mathrm{mL}) / 90(\mathrm{~mm})$.

\section{Mice}

C57BL/6 mice were purchased from Charles River Laboratories. Mice were age-matched and used between 8 and 16 weeks of age. Mice were housed in microisolator cages with food and water available ad libitum. All experimental protocols were reviewed and approved by the University of Tennessee Health Science Center IACUC.

\section{Intranasal Challenge of Mice with FT}

Mice were lightly anesthetized using isoflurane administered with a Vapor Stick nebulizer. Frozen stocks of FT were thawed anew for each experiment, diluted in phosphate-buffered saline (PBS), and administered intranasally ( $20 \mu \mathrm{l} /$ naris). The CFUs of FT in the inocula were verified by dilution plating. Following challenge, all mice were monitored daily for signs of illness (decreased mobility, ruffled fur, hunched gait) and weight loss. Upon sacrifice, bronchoalveolar lavage was performed and spleens, livers and lungs were collected for bacterial burden assessment.

\section{Bacterial Burden Determination}

Spleens, livers and lungs of challenged mice were removed aseptically and homogenized (using a tissue homogenizer) in one milliliter of sterile PBS. To disrupt cells (releasing
FT), $0.25 \mathrm{~mL}$ disruption buffer (2.5\% saponin, 15\% BSA, in PBS) was added with light vortexing. Appropriate dilutions of each sample were then plated in duplicate using an Eddy Jet spiral plater (Neutec Group Inc., Farmingdale, NY) on MMH agar plates (supplemented with 5\% calf serum) and incubated at $37^{\circ} \mathrm{C}$ for $48-72$ hours. Colonies were counted using a Flash \& Go automated colony counter (Neutec Group Inc.).

\section{Cell Culture, Macrophage Infection, and Cytotoxicity Assays}

J774 and RAW264.7 cells (ATCC) were propagated in Dulbecco's Modified Eagle's Medium (DMEM) containing $10 \%$ fetal bovine serum. For replication assays, cells were seeded in 24 well tissue culture plates at a density of $2 \times 10^{5}$ cells per well. Twenty-four-hours later, FT was added (MOI of 10) and incubated for $2 \mathrm{~h}$. Gentamicin was then added $(50 \mu \mathrm{g} / \mathrm{mL})$ and incubated for 1 hour to kill extracellular bacteria. Cells were then washed two times with DMEM and incubated in fresh culture medium at $37^{\circ} \mathrm{C}$. At each experimental time point, cells were washed with PBS to remove any bacteria released during the incubation period, lysed in PBS containing $0.1 \%$ deoxycholate, and the number of viable bacteria released from the cells was determined via dilution plating.

For cytotoxicity (LDH) assays, J774 cells were seeded into a 96 well plates and allowed to adhere overnight. FT was added to wells (MOI of 100) and the plates were centrifuged $(800 \times \mathrm{g}, 5 \mathrm{~min})$ to facilitate contact between the cells and bacteria. After 2 hours of co-culture with bacteria, the culture supernatant was aspirated and replaced with fresh media containing gentamicin $(50 \mu \mathrm{g} / \mathrm{mL})$ and the plates were incubated at $37^{\circ} \mathrm{C}, 5 \% \mathrm{CO}_{2}$ for $24 \mathrm{hrs}$. Culture supernatants were then analyzed for $\mathrm{LDH}$ release using the CytoTox Non-Radioactive Cytotoxicity Assay (Promega) according to the manufacturer's protocol. The total LDH release (100\% LDH in cells) was determined by lysis of uninfected cells. The background $\mathrm{LDH}$ value was defined as the level of LDH in the supernatants collected from intact uninfected cells. The percentage of LDH release was calculated as follows: (Sample LDH value background LDH value)/(Total LDH release value - Background $\mathrm{LDH}$ release value) $\times 100$.

Mouse bone marrow-derived dendritic cells (BMDC) were generated by incubating bone marrow in RPMI 1640-10\%FCS supplemented with rmGM-CSF $(20 \mathrm{ng} / \mathrm{mL})$ (R\&D Systems, Minneapolis, MN) for 8 days. This procedure routinely results in $60-80 \% \mathrm{CD}_{11 \mathrm{c}^{+}}$cells.

\section{Bronchoalveolar Lavage (BAL) and Flow Cytometric Analysis}

BAL was performed as described previously [45]. Briefly, BAL was performed by intratracheal injection of $1 \mathrm{~mL}$ of PBS into the lungs with immediate vacuum aspiration. 
The amount of fluid (BALF) recovered was routinely around $800 \mu$ l. Cells were recovered from BALF by centrifugation and their viability was determined by trypan blue exclusion. Protease inhibitor cocktail (Pierce, Rockford, IL) was added to the BALF immediately after recovery and the BALF was frozen at $-80^{\circ} \mathrm{C}$ till further use.

Flow cytometry was performed on isolated BAL cells using fluorochrome conjugated antibodies specific for CD45, CD11b, F4/80, GR1, and NK1.1 (eBioscience CA, USA). A minimum of 50,000 events/sample was collected on a BD Biosciences LSRII cytometer (BD Biosciences, San Jose, CA). Expression of cell surface markers was analyzed using DIVA software. The percentage of neutrophils was determined using gates set on live cells and CD45 expression, and neutrophils were identified as $\mathrm{CD} 11 \mathrm{~b}^{\text {high }} / \mathrm{Gr} \mathrm{1}^{\text {high }}$. Dendritic cells and NK cells were identified as CD11b ${ }^{\text {high }}$ / $\mathrm{GR} 1^{\mathrm{lo}} / \mathrm{F} 480^{\mathrm{lo}}$ and $\mathrm{CD} 45^{\text {high }} / \mathrm{NK} 1.1^{\text {high }}$, respectively.

\section{Chemokine/Cytokine Measurements from BALF}

The concentrations of each of the chemokines/cytokines from BALF were determined via multiplex analysis using a Luminex Milliplex Analyzer (Millipore Corp., Billerica, MA). A 32-plex Milliplex Cytokine/Chemokine Immunoassay (Millipore) was used according to manufacturer's instructions to simultaneously measure the following: eotaxin, G-CSF, GM-CSF, IFN- $\gamma$, IL- $1 \alpha$, IL- $1 \beta$, IL-2, IL-3, IL-4, IL-5, IL-6, IL-7, IL-9, IL-10, IL-12 (p40), IL-12 (p70), IL-13, IL-15, IL-17, IP-10, KC, LIF, LIX, MCP-1, M-CSF, MIG, MIP-1 $\beta$, MIP- $1 \alpha$, MIP-2, RANTES, TNF $\alpha$, and VEGF. All determinations were performed with duplicate samples, and data analysis was performed using Luminex xPonent and Milliplex Analyst software packages (Millipore).

\section{Galactose Sensitivity}

FT strains were grown overnight in MHB containing 0.1\% glucose and then pelleted, washed and resuspended in PBS. Each strain was then diluted to $5 \times 10^{7} \mathrm{CFU} / \mathrm{mL}$ and inoculated in fresh MHB containing either $0.1 \%$ glucose or $2 \% \mathrm{D}$-galactose as the sole sugar source and incubated at $37^{\circ} \mathrm{C}$ for 24 hours. Optical density at $600 \mathrm{~nm}$ was monitored hourly as a measure of growth.

\section{LPS Isolation}

Bacterial cultures in mid-logarithmic growth phase were pelleted by centrifugation at $4000 \mathrm{rpm}$ for $20 \mathrm{~min}$ and then resuspended in PBS. LPS was isolated from the bacteria using LPS extraction kit (Intron Biotechnologies, Boca Raton, FL) as per the manufacturer's directions.

\section{SDS-PAGE and Western Blotting}

Bacterial cell lysates ( $5 \mu \mathrm{g} / \mathrm{lane})$ and LPS extracts were electrophoresed on 4-20\% gradient polyacrylamide gel and transferred to nitrocellulose membrane. The membrane was then blocked with $5 \%$ BSA (in PBS+0.1\% Tween-20) and probed with an FT LVS O-antigen-specific mAb (unpublished, see below). Bound antibodies were detected by probing with HRP-conjugated goat anti-mouse secondary antibody (Jackson Research Labs) and visualized by addition of Western Lightning PlusECL Enhanced Chemiluminescence substrate (Perkin Elmer, Shelton, CT).

The O-antigen-specific mAb used for the Western analysis was generated as follows: Six-week old female C57/BL6 mice were immunized (i.p.) three times at two-week intervals with $5 \times 10^{7}$ heat-killed FTLVS. Three weeks later each mouse was challenged/boosted via intraperitoneal inoculation with $10^{6}$ live FTLVS. Six weeks later, the FT immune mice with high titer antiFT IgG were boosted via intraperitoneal injection of $5 \times$ $10^{7}$ heat-killed FTLVS. Spleens were removed three days later, and splenocytes were fused with P3 $\times 63$ Ag8.653 plasmacytoma cells as previously described [67]. Thirteen days after fusion, hybridoma cell supernatants were screened via direct ELISA for IgG reactive with sonicated FT-antigen and whole FT bacteria. The $\mathrm{O}$-antigen-specific hybridoma was cloned via limiting dilution and mAbs were purified from culture supernatants via affinity chromatography using protein Gsepharose columns (Pierce/ThermoFisher Scientific, Rockford, IL).

\section{Sensitivity to Human Serum}

Overnight cultures of the indicated FT strains were pelleted via centrifugation at $4000 \mathrm{rpm}$ for $20 \mathrm{~min}$ and washed once with PBS. The bacteria $\left(1 \times 10^{7} \mathrm{CFU}\right)$ were suspended in $100 \mu \mathrm{l}$ PBS and incubated with an equal amount of human fresh frozen plasma (citrate was used as the anticoagulant) at varying concentrations for $2 \mathrm{~h}$ at $37^{\circ} \mathrm{C}$. Surviving bacteria were enumerated by dilution plating on $\mathrm{MMH}$ plates.

\section{TLR4/TLR2 Signaling Luciferase Assay}

HeLa-TLR4/MD2 or HeLa-TLR2 [68] were transiently transfected in 24-well plates using Effectene reagent (Qiagen) with $0.4 \mu \mathrm{g}$ of ELAM-luciferase, $0.2 \mu \mathrm{g}$ of pcDNACD14 and $0.1 \mu \mathrm{g}$ of CMV- $\beta$-Gal expression plasmids (recipe for 24 wells). Forty-eight hours after transfection, the cells were stimulated for 6 hours with FT lysates. LPS (10 ng/mL) from $\boldsymbol{E}$. coli strain LCD25 (List Biological, Campbell, CA) and PAM3-Cys $(1 \mu \mathrm{g} / \mathrm{mL}$; Invivogen, San Diego, CA) were used as controls for TLR4 and TLR2 signaling, respectively. Luciferase assays were performed using Promega (Madison, WI) reagents according to the manufacturer recommendations. Efficiency of transfection was normalized by measuring $\beta$-Gal in cell lysates. 


\section{RNase Protection Assays}

BMDC seeded into 24-well tissue culture plates $(2 \times$ $10^{6} /$ well) were infected with FT and then total RNA was isolated $8 \mathrm{hr}$ later using TRizol reagent (Life Technologies, Grand Island, NY). RNase protection assays were performed with $4 \mu \mathrm{g}$ of total RNA using a BD-Pharmingen (San Diego, CA) Riboquant kit and the mCK-2 multi-probe template set.

\section{Quantitation of IL-1 $\beta$ Production In Vitro}

BMDC or THP-1 cells were seeded into 24-well tissue culture plates $\left(2 \times 10^{6} /\right.$ well $)$ and infected with FT. Gentamicin was added to the medium 3 hours later. IL- $1 \beta$ was measured in conditioned supernatants $24 \mathrm{hr}$ postinfection using an ELISA kit (eBiosciences, San Diego, CA).

\section{Statistical Methodology}

Statistical analyses of each figure were performed using GraphPad Prism software (GraphPad Software, La Jolla, CA). The specific statistical method used for each dataset is described in the figure legends.

\section{List of Abbreviations}

FT: Francisella tularensis; LVS: live vaccine strain; FTLVS: Francisella tularensis live vaccine strain; $L_{50}$ : lethal dose 50; CAMPs: cationic antimicrobial peptides; LPS: lipopolysaccharide; WT: wild type; MHB: Muller-Hinton Broth; MMH: modified Mueller-Hinton Broth; PBS: phosphate-buffered saline (PBS),; BAL: Bronchoalveolar lavage; BALF: bronchiolar lavage fluid; BMDC: bone marrow-derived dendritic cells.

\section{Acknowledgements and Funding}

The project described was supported by NIH grant \#U54 Al057157 from Southeastern Regional Center of Excellence for Emerging Infections and Biodefense, by NIH grants Al079482 (to JEB) and Al061260 (to MAM), and by Department of Defense Army grant W81XHW-05-1-0227. The authors also thank Janice Collum and Tim Higgins for their technical assistance.

\section{Author details}

'Department of Microbiology, Immunology, and Biochemistry, The University of Tennessee Health Science Center, 858 Madison Avenue, Memphis, Tennessee 38163, USA. ${ }^{2}$ Department of Immunology and Microbial Sciences, The Scripps Research Institute, 10550 North Torrey Pines Road, La Jolla, CA 92037, USA.

\section{Authors' contributions}

HRJ conceived of and performed most of the experimental work for the study and drafted the manuscript. JP participated in the bulk of the experimental work. EAF participated in and assisted in design of the flow cytometric analyses. JEB and XRB created the transposon library and isolated the galU mutant strain of FTLVS. FR assisted in design of and performance of RNase protection and IL-1 $\beta$ measurements from infected cells in vitro. FDE performed the antimicrobial sensitivity assays. MAM oversaw the design and coordination of all studies, performed the statistical analyses, and helped to draft the manuscript. All authors have read and approved the final manuscript.

\section{Competing interests}

The authors declare that they have no competing interests.

Received: 6 April 2011 Accepted: 5 August 2011

Published: 5 August 2011

\section{References}

1. Dennis DT, Inglesby TV, Henderson DA, Bartlett JG, Ascher MS, Eitzen E, Fine AD, Friedlander AM, Hauer J, Layton M, et al: Tularemia as a biological weapon: medical and public health management. JAMA 2001, 285(21):2763-2773

2. Twine S, Bystrom M, Chen W, Forsman M, Golovliov I, Johansson A, Kelly J, Lindgren $\mathrm{H}$, Svensson K, Zingmark $\mathrm{C}$, et al: A mutant of Francisella tularensis strain SCHU S4 lacking the ability to express a 58-kilodalton protein is attenuated for virulence and is an effective live vaccine. Infect Immun 2005, 73(12):8345-8352.

3. Saslaw S, Eigelsbach HT, Prior JA, Wilson HE, Carhart S: Tularemia vaccine study. II. Respiratory challenge. Arch Intern Med 1961, 107:702-714.

4. Saslaw S, Eigelsbach HT, Wilson HE, Prior JA, Carhart S: Tularemia vaccine study. I. Intracutaneous challenge. Arch Intern Med 1961, 107:689-701.

5. Eigelsbach HT, Downs CM: Prophylactic effectiveness of live and killed tularemia vaccines. I. Production of vaccine and evaluation in the white mouse and guinea pig. J Immunol 1961, 87:415-425.

6. Larsson P, Oyston PC, Chain P, Chu MC, Duffield M, Fuxelius HH, Garcia E, Halltorp G, Johansson D, Isherwood KE, et al: The complete genome sequence of Francisella tularensis, the causative agent of tularemia. Nat Genet 2005, 37(2):153-159.

7. Gallagher LA, Ramage E, Jacobs MA, Kaul R, Brittnacher M, Manoil C: A comprehensive transposon mutant library of Francisella novicida, a bioweapon surrogate. Proc Natl Acad Sci USA 2007, 104(3):1009-1014.

8. Su J, Yang J, Zhao D, Kawula TH, Banas JA, Zhang JR: Genome-wide identification of Francisella tularensis virulence determinants. Infect Immun 2007, 75(6):3089-3101.

9. Anthony LD, Burke RD, Nano FE: Growth of Francisella spp. in rodent macrophages. Infect Immun 1991, 59(9):3291-3296.

10. Clemens DL, Lee BY, Horwitz MA: Virulent and avirulent strains of Francisella tularensis prevent acidification and maturation of their phagosomes and escape into the cytoplasm in human macrophages. Infect Immun 2004, 72(6):3204-3217.

11. Golovliov I, Baranov V, Krocova Z, Kovarova H, Sjostedt A: An attenuated strain of the facultative intracellular bacterium Francisella tularensis can escape the phagosome of monocytic cells. Infect Immun 2003, 71(10):5940-5950.

12. Santic M, Molmeret M, Klose KE, Jones S, Kwaik YA: The Francisella tularensis pathogenicity island protein IglC and its regulator MglA are essential for modulating phagosome biogenesis and subsequent bacterial escape into the cytoplasm. Cell Microbiol 2005, 7(7):969-979.

13. Qin A, Scott DW, Thompson JA, Mann BJ: Identification of an essential Francisella tularensis subsp. tularensis virulence factor. Infect Immun 2009, 77(1):152-161.

14. Gil H, Platz GJ, Forestal CA, Monfett M, Bakshi CS, Sellati TJ, Furie MB, Benach JL, Thanassi DG: Deletion of TolC orthologs in Francisella tularensis identifies roles in multidrug resistance and virulence. Proc Natl Acad Sci USA 2006, 103(34):12897-12902.

15. Bina $X R$, Lavine $C L$, Miller MA, Bina JE: The AcrAB RND efflux system from the live vaccine strain of Francisella tularensis is a multiple drug efflux system that is required for virulence in mice. FEMS Microbiol Lett 2008, 279(2):226-233.

16. Mohapatra NP, Soni S, Bell BL, Warren R, Ernst RK, Muszynski A, Carlson RW, Gunn JS: Identification of an orphan response regulator required for the virulence of Francisella spp. and transcription of pathogenicity island genes. Infect Immun 2007, 75(7):3305-3314.

17. Wang X, Ribeiro AA, Guan Z, Abraham SN, Raetz CR: Attenuated virulence of a Francisella mutant lacking the lipid A 4'-phosphatase. Proc Natl Acad Sci USA 2007, 104(10):4136-4141.

18. Vinogradov $\mathrm{E}$, Perry MB, Conlan JW: Structural analysis of Francisella tularensis lipopolysaccharide. Eur J Biochem 2002, 269(24):6112-6118.

19. Phillips NJ, Schilling B, McLendon MK, Apicella MA, Gibson BW: Novel modification of lipid A of Francisella tularensis. Infect Immun 2004, 72(9):5340-5348.

20. Kanistanon D, Hajjar AM, Pelletier MR, Gallagher LA, Kalhorn T, Shaffer SA, Goodlett DR, Rohmer L, Brittnacher MJ, Skerrett SJ, et al: A Francisella mutant in lipid A carbohydrate modification elicits protective immunity. PLoS Pathog 2008, 4(2):e24.

21. Bosio CM, Bielefeldt-Ohmann H, Belisle JT: Active suppression of the pulmonary immune response by Francisella tularensis Schu4. J Immunol 2007, 178(7):4538-4547. 
22. Hall JD, Woolard MD, Gunn BM, Craven RR, Taft-Benz S, Frelinger JA Kawula TH: Infected-host-cell repertoire and cellular response in the lung following inhalation of Francisella tularensis Schu S4, LVS, or U112. Infect Immun 2008, 76(12):5843-5852.

23. Mares CA, Ojeda SS, Li Q, Morris EG, Coalson JJ, Teale JM: Aged mice display an altered pulmonary host response to Francisella tularensis live vaccine strain (LVS) infections. Exp Gerontol 2010, 45(2):91-96.

24. Malik M, Bakshi CS, McCabe K, Catlett SV, Shah A, Singh R, Jackson PL, Gaggar A, Metzger DW, Melendez JA, et al: Matrix metalloproteinase 9 activity enhances host susceptibility to pulmonary infection with type $A$ and B strains of Francisella tularensis. J Immunol 2007, 178(2):1013-1020.

25. Mares CA, Ojeda SS, Morris EG, Li Q, Teale JM: Initial delay in the immune response to Francisella tularensis is followed by hypercytokinemia characteristic of severe sepsis and correlating with upregulation and release of damage-associated molecular patterns. Infect Immun 2008, 76(7):3001-3010.

26. Kirimanjeswara GS, Olmos S, Bakshi CS, Metzger DW: Humoral and cellmediated immunity to the intracellular pathogen Francisella tularensis. Immunol Rev 2008, 225:244-255.

27. Chang HY, Lee JH, Deng WL, Fu TF, Peng HL: Virulence and outer membrane properties of a galU mutant of Klebsiella pneumoniae CG43. Microb Pathog 1996, 20(5):255-261.

28. Choudhury B, Carlson RW, Goldberg JB: The structure of the lipopolysaccharide from a galU mutant of Pseudomonas aeruginosa serogroup-011. Carbohydr Res 2005, 340(18):2761-2772.

29. Genevaux P, Bauda P, DuBow MS, Oudega B: Identification of Tn10 insertions in the $r f a G, r f a P$, and galU genes involved in lipopolysaccharide core biosynthesis that affect Escherichia coli adhesion. Arch Microbiol 1999, 172(1):1-8.

30. Mollerach M, Lopez R, Garcia E: Characterization of the galU gene of Streptococcus pneumoniae encoding a uridine diphosphoglucose pyrophosphorylase: a gene essential for capsular polysaccharide biosynthesis. J Exp Med 1998, 188(11):2047-2056.

31. Nesper J, Lauriano CM, Klose KE, Kapfhammer D, Kraiss A, Reidl J: Characterization of Vibrio cholerae $\mathrm{O} 1 \mathrm{El}$ tor galU and galE mutants: influence on lipopolysaccharide structure, colonization, and biofilm formation. Infect Immun 2001, 69(1):435-445.

32. Sandlin RC, Lampel KA, Keasler SP, Goldberg MB, Stolzer AL, Maurelli AT: Avirulence of rough mutants of Shigella flexneri: requirement of $O$ antigen for correct unipolar localization of IcsA in the bacterial outer membrane. Infect Immun 1995, 63(1):229-237.

33. Boels IC, Ramos A, Kleerebezem M, de Vos WM: Functional analysis of the Lactococcus lactis galU and galE genes and their impact on sugar nucleotide and exopolysaccharide biosynthesis. Appl Environ Microbiol 2001, 67(7):3033-3040.

34. Daran JM, Dallies N, Thines-Sempoux D, Paquet V, Francois J: Genetic and biochemical characterization of the UGP1 gene encoding the UDPglucose pyrophosphorylase from Saccharomyces cerevisiae. European journal of biochemistry/FEBS 1995, 233(2):520-530.

35. Moser B, Clark-Lewis I, Zwahlen R, Baggiolini M: Neutrophil-activating properties of the melanoma growth-stimulatory activity. J Exp Med 1990, 171(5):1797-1802.

36. Thomas J, Liu F, Link DC: Mechanisms of mobilization of hematopoietic progenitors with granulocyte colony-stimulating factor. Curr Opin Hematol 2002, 9(3):183-189.

37. Taub DD, Lloyd AR, Conlon K, Wang JM, Ortaldo JR, Harada A, Matsushima K, Kelvin DJ, Oppenheim JJ: Recombinant human interferoninducible protein 10 is a chemoattractant for human monocytes and $\mathrm{T}$ lymphocytes and promotes $\mathrm{T}$ cell adhesion to endothelial cells. J Exp Med 1993, 177(6):1809-1814.

38. Lukacs NW, Strieter RM, Chensue SW, Widmer M, Kunkel SL: TNF-alpha mediates recruitment of neutrophils and eosinophils during airway inflammation. J Immunol 1995, 154(10):5411-5417.

39. Wolpe SD, Davatelis G, Sherry B, Beutler B, Hesse DG, Nguyen HT, Moldawer LL, Nathan CF, Lowry SF, Cerami A: Macrophages secrete a novel heparin-binding protein with inflammatory and neutrophil chemokinetic properties. J Exp Med 1988, 167(2):570-581.

40. Wolpe SD, Sherry B, Juers D, Davatelis G, Yurt RW, Cerami A: Identification and characterization of macrophage inflammatory protein 2. Proc Natl Acad Sci USA 1989, 86(2):612-616.
41. Xu LL, Warren MK, Rose WL, Gong W, Wang JM: Human recombinant monocyte chemotactic protein and other C-C chemokines bind and induce directional migration of dendritic cells in vitro. J Leukoc Biol 1996, 60(3):365-371.

42. Fernandes-Alnemri T, Yu JW, Juliana C, Solorzano L, Kang S, Wu J, Datta P, McCormick M, Huang L, McDermott E, et al: The AIM2 inflamma some is critical for innate immunity to Francisella tularensis. Nat Immunol 2010, 11(5):385-393.

43. Vilches S, Canals R, Wilhelms M, Salo MT, Knirel YA, Vinogradov E, Merino S, Tomas JM: Mesophilic Aeromonas UDP-glucose pyrophosphorylase (GalU) mutants show two types of lipopolysaccharide structures and reduced virulence. Microbiology 2007, 153(Pt 8):2393-2404.

44. Priebe GP, Dean CR, Zaidi T, Meluleni GJ, Coleman FT, Coutinho YS, Noto MJ, Urban TA, Pier GB, Goldberg JB: The galU Gene of Pseudomonas aeruginosa is required for corneal infection and efficient systemic spread following pneumonia but not for infection confined to the lung. Infect Immun 2004, 72(7):4224-4232.

45. Nance SC, Yi AK, Re FC, Fitzpatrick EA: MyD88 is necessary for neutrophil recruitment in hypersensitivity pneumonitis. J Leukoc Biol 2008, 83(5):1207-1217.

46. Tsai WC, Strieter RM, Mehrad B, Newstead MW, Zeng X, Standiford TJ: CXC chemokine receptor CXCR2 is essential for protective innate host response in murine Pseudomonas aeruginosa pneumonia. Infect Immun 2000, 68(7):4289-4296.

47. Greenberger MJ, Strieter RM, Kunkel SL, Danforth JM, Laichalk LL, McGillicuddy DC, Standiford TJ: Neutralization of macrophage inflammatory protein-2 attenuates neutrophil recruitment and bacterial clearance in murine Klebsiella pneumonia. J Infect Dis 1996, 173(1):159-165.

48. Sjostedt A, Conlan JW, North RJ: Neutrophils are critical for host defense against primary infection with the facultative intracellular bacterium Francisella tularensis in mice and participate in defense against reinfection. Infect Immun 1994, 62(7):2779-2783.

49. Duenas Al, Aceves M, Orduna A, Diaz R, Sanchez Crespo M, GarciaRodriguez C: Francisella tularensis LPS induces the production of cytokines in human monocytes and signals via Toll-like receptor 4 with much lower potency than E. coli LPS. Int Immunol 2006, 18(5):785-795.

50. Chen W, KuoLee R, Shen H, Busa M, Conlan JW: Toll-like receptor 4 (TLR4) does not confer a resistance advantage on mice against low-dose aerosol infection with virulent type A Francisella tularensis. Microb Pathog 2004, 37(4):185-191.

51. Ancuta P, Pedron T, Girard R, Sandstrom G, Chaby R: Inability of the Francisella tularensis lipopolysaccharide to mimic or to antagonize the induction of cell activation by endotoxins. Infect Immun 1996, 64(6):2041-2046

52. Cole LE, Shirey KA, Barry E, Santiago A, Rallabhandi P, Elkins KL, Puche AC, Michalek SM, Vogel SN: Toll-like receptor 2-mediated signaling requirements for Francisella tularensis live vaccine strain infection of murine macrophages. Infect Immun 2007, 75(8):4127-4137.

53. Li H, Nookala S, Bina XR, Bina JE, Re F: Innate immune response to Francisella tularensis is mediated by TLR2 and caspase- 1 activation. $J$ Leukoc Biol 2006, 80(4):766-773

54. Malik M, Bakshi CS, Sahay B, Shah A, Lotz SA, Sellati TJ: Toll-like receptor 2 is required for control of pulmonary infection with Francisella tularensis. Infect Immun 2006, 74(6):3657-3662.

55. Thakran S, Li H, Lavine CL, Miller MA, Bina JE, Bina XR, Re F: Identification of Francisella tularensis lipoproteins that stimulate the toll-like receptor (TLR)2/TLR1 heterodimer. J Biol Chem 2008, 283(7):3751-3760.

56. Dean CR, Goldberg JB: Pseudomonas aeruginosa galU is required for a complete lipopolysaccharide core and repairs a secondary mutation in a PA103(serogroup 011) wbpM mutant. FEMS Microbiol Lett 2002, 210(2):277-283.

57. Clay CD, Soni S, Gunn JS, Schlesinger LS: Evasion of complementmediated lysis and complement C3 deposition are regulated by Francisella tularensis lipopolysaccharide $\mathrm{O}$ antigen. J Immunol 2008 , 181(8):5568-5578.

58. Jones JW, Kayagaki N, Broz P, Henry T, Newton K, O'Rourke K, Chan S, Dong J, Qu Y, Roose-Girma M, et al: Absent in melanoma 2 is required for innate immune recognition of Francisella tularensis. Proc Natl Acad Sci USA 2010, 107(21):9771-9776. 
59. Rathinam VA, Jiang Z, Waggoner SN, Sharma S, Cole LE, Waggoner L, Vanaja SK, Monks BG, Ganesan S, Latz E, et al: The AIM2 inflammasome is essential for host defense against cytosolic bacteria and DNA viruses. Nat Immunol 2010, 11(5):395-402.

60. Willingham SB, Bergstralh DT, O'Connor W, Morrison AC, Taxman DJ, Duncan JA, Barnoy S, Venkatesan MM, Flavell RA, Deshmukh M, et al: Microbial pathogen-induced necrotic cell death mediated by the inflammasome components CIAS1/cryopyrin/NLRP3 and ASC. Cell Host Microbe 2007, 2(3):147-159.

61. Platz GJ, Bublitz DC, Mena P, Benach JL, Furie MB, Thanassi DG: A tolC mutant of Francisella tularensis is hypercytotoxic compared to the wild type and elicits increased proinflammatory responses from host cells. Infect Immun 2010, 78(3):1022-1031.

62. Weiss DS, Henry T, Monack DM: Francisella tularensis: activation of the inflamma some. Ann N Y Acad Sci 2007, 1105:219-237.

63. Ulland TK, Buchan BW, Ketterer MR, Fernandes-Alnemri T, Meyerholz DK, Apicella MA, Alnemri ES, Jones BD, Nauseef WM, Sutterwala FS: Cutting edge: mutation of Francisella tularensis mviN leads to increased macrophage absent in melanoma 2 inflamma some activation and a loss of virulence. J Immunol 2010, 185(5):2670-2674.

64. Huang MT, Mortensen BL, Taxman DJ, Craven RR, Taft-Benz S, Kijek TM, Fuller JR, Davis BK, Allen IC, Brickey WJ, et al: Deletion of ripA alleviates suppression of the inflammasome and MAPK by Francisella tularensis. Immunol 2010, 185(9):5476-5485.

65. Bina XR, Wang C, Miller MA, Bina JE: The Bla2 beta-lactamase from the live-vaccine strain of Francisella tularensis encodes a functional protein that is only active against penicillin-class beta-lactam antibiotics. Arch Microbiol 2006, 186(3):219-228.

66. Curiale MS, Levy SB: Two complementation groups mediate tetracycline resistance determined by Tn10. J Bacterio/ 1982, 151(1):209-215.

67. Marion TN, Lawton AR, Kearney JF, Briles DE: Anti-DNA autoantibodies in $(\mathrm{NZB} \times \mathrm{NZW}) \mathrm{F} 1$ mice are clonally heterogeneous, but the majority share a common idiotype. J Immunol 1982, 128(2):668-674.

68. Re F, Strominger JL: Toll-like receptor 2 (TLR2) and TLR4 differentially activate human dendritic cells. J Biol Chem 2001, 276(40):37692-37699.

doi:10.1186/1471-2180-11-179

Cite this article as: Jayakar et al:. A galU mutant of francisella tularensis is attenuated for virulence in a murine pulmonary model of tularemia. BMC Microbiology 2011 11:179.

\section{Submit your next manuscript to BioMed Central and take full advantage of:}

- Convenient online submission

- Thorough peer review

- No space constraints or color figure charges

- Immediate publication on acceptance

- Inclusion in PubMed, CAS, Scopus and Google Scholar

- Research which is freely available for redistribution

Submit your manuscript at www.biomedcentral.com/submit
Biomed Central 